This item was submitted to Loughborough's Institutional Repository (https://dspace.lboro.ac.uk/) by the author and is made available under the following Creative Commons Licence conditions.

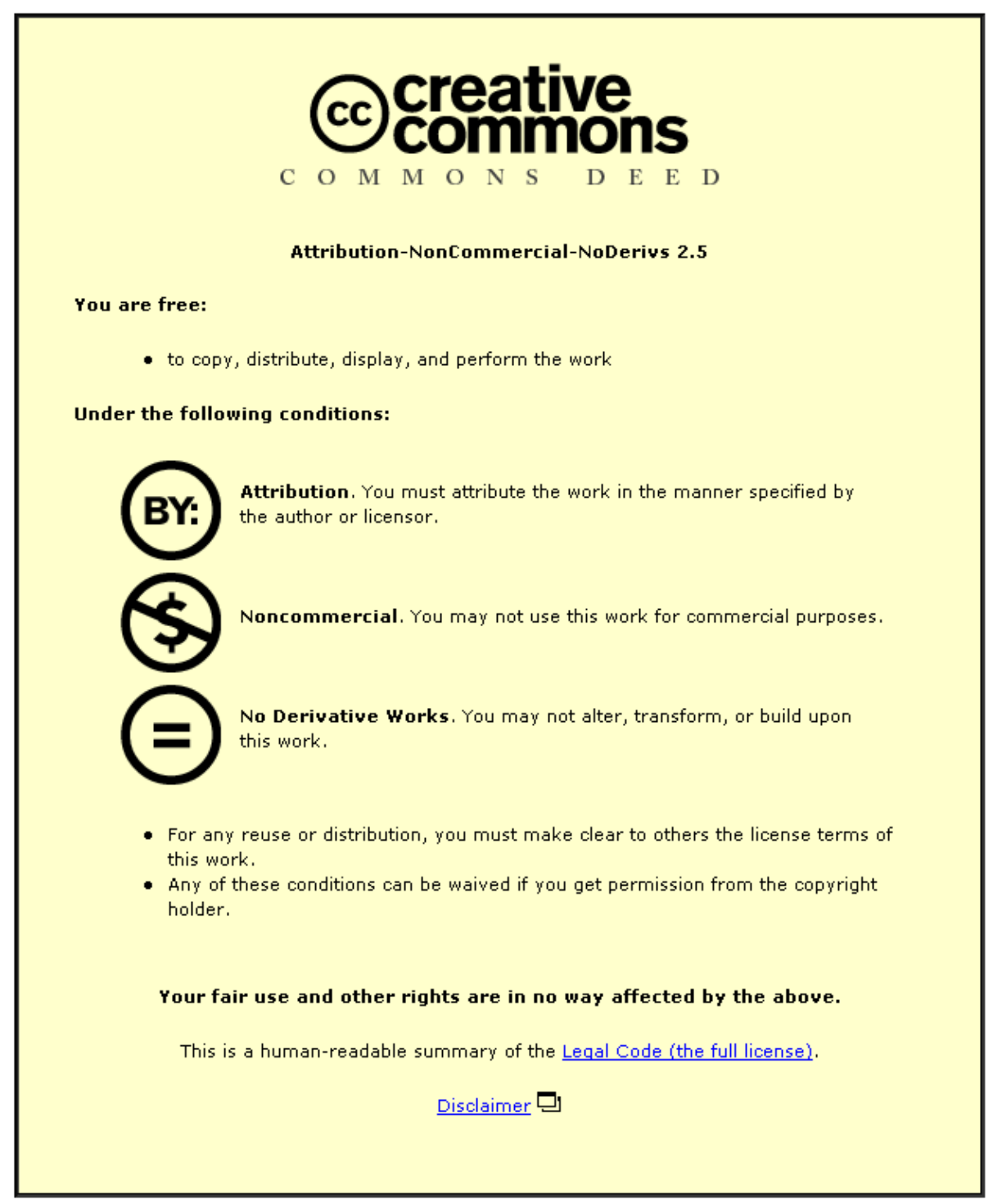

For the full text of this licence, please go to: http://creativecommons.org/licenses/by-nc-nd/2.5/ 


\title{
Quantifying and characterising aviation accident risk factors
}

\author{
D.K.Y. Wong ${ }^{1}$, D.E. Pitfield, R.E. Caves, A.J. Appleyard \\ Transport Studies Group, Civil \& Building Engineering Dept. \\ Loughborough University, Loughborough, LE11 3TU U.K.
}

\begin{abstract}
This paper compares normal flights' exposure to a number of meteorological factors with the equivalent for certain accident flights. The factors examined include visibility, ceiling height, temperature, crosswind, tailwind and instrument or visual meteorological conditions. Differences in exposure and to measure accident propensity related to different levels of risk exposure are quantified based on relative accident involvement ratios. Four categories of aircraft accidents relevant to the assessment of airport safety are examined.
\end{abstract}

Key words: aviation accidents; normal operations data; risk exposure; relative accident involvement ratio

\section{INTRODUCTION}

The Air France landing overrun at Toronto airport in August 2005 as well as the Southwest incident at Chicago Midway in December later that year once again brought the media's attention to the debate on the adequacy of airport safety areas (ASA). ASAs are developed by international as well as local aviation authorities to protect passengers as well as nearby communities at and near airports. Examples of ASAs include the runway strip, runway end safety area (RESA) and runway protection zone. They are intended to mitigate against the risks of landing overruns (LDOR), landing undershoots (LDUS), take-off overruns (TOOR) and crashes after take-off (TOC). These are the major types of accidents that occur during the take-off and landing phases of flight and account for $90 \%$ of aviation accidents (Ashford 1998).

The application and dimensions of ASAs lack international agreement are, however, often rigidly determined and insensitive to the risks and needs of specific airports. While insufficient safety areas may endanger lives in case of an accident, their over-cautious use may equally limit the potential of the airport. Doubts over the effectiveness and necessity of such areas have been voiced by property developers and environmentalists.

\section{ANALYSIS WITH NORMAL OPERATIONS DATA}

An important step in assessing the adequacy of ASAs is to evaluate the likelihood of accident occurrence under different airport environments. This involves studying the nature of risk factors and quantifying their criticality. Previous work on the subject have been handicapped by the lack of data on normal, incident-free flights' exposure to risk (Piers et al. 1993, Khatwa and Helmreich 1998). In the absence of this information, even

\footnotetext{
${ }^{1}$ Corresponding author, E-mail: k.y.wong@lboro.ac.uk
} 
though the occurrence of a factor (e.g. contaminated runway) may be identified as a contributor to many accidents, it is impossible to know how critical the factor is since many other flights may have also experienced it without incident. With normal operations data (NOD), the number of operations that experience the factor could be taken into account so risk ratios can be generated and their importance quantified.

A previous attempt to use NOD to assess aviation accident risk by Enders et al. 1996 concerns approach and landing accidents and compared the presence of high terrain and availability of various airport navigational aids between normal flights and accidents. Kirkland (2004) modelled the occurrence of aircraft overruns based on the difference in weight and runway criticality between normal and accident flights. While the two pieces contribute to a better understanding of the factors behind accident occurrence, both identified exposure to meteorological conditions as a prime area warranting further research.

Here we compare normal flights' exposure to meteorological conditions with that of accidents'. Specifically, we explore whether accident flights and normal flights are exposed to statistically different meteorological conditions, and if so, measure the accident propensity under different levels of exposure. The first objective is achieved by chi-square analysis and t-tests while accident propensity is calculated using the Relative Accident Involvement Ratios (RAIR). Key weather parameters are thus quantified and characterised as aviation accident risk factors. The analysis was carried out independently for the four accidents types related to ASAs, such that their occurrence characteristics may be individually understood and contrasted. The specific results of this paper pertains to a preliminary

\section{DATA}

A comprehensive database of four accident types since 1982 is constructed using data from the US National Transportation Safety Board (NTSB). Intuitively, not all accidents are influenced by meteorological conditions, e.g. a purely mechanically induced accident. Not all accident, therefore, are relevant to understanding the nature and criticality of weather parameters as risk factors. If all accident cases were used in the analysis, the "redundant" cases would lead to inaccurate results and misleading conclusions on the criticality of weather-related risk factors. To identify cases relevant to this research, the NTSB list of accident causes and factors was used. The full list of causes and factors was reviewed to identify all meteorological events, including icing conditions. An accident that involves any of these events is considered as weather-related - 283 such accidents were identified.

The US Federal Aviation Administration (FAA) (2002) Aviation System Performance Metrics (ASPM) database is used as a source of data on normal flights' exposure to weather conditions. ASPM records in 15-minute segments the weather condition, the particular combination of runways used for take-offs and landings as well as the arrival and departure counts. Movements at 9 airports, for selected months over 2 years, are used as the NOD sample. The months of February, May, August and November were used to represent the seasonal changes in weather and the airports selected also reflect regional 
meteorological differences. Table 1 lists the sample airports and their respective sampling periods. The sample includes 323,487 normal flight operations.

Table 1 Airports and sample period

\begin{tabular}{|l|l|}
\hline Airport Code & Sample Month \\
\hline LGA & August 2004 \\
\hline MSP & February 2004 \\
\hline ATL & May 2004 \\
\hline TPA & November 2004 \\
\hline PHX & August 2003 \\
\hline SEA & Febebruary 2003 \\
\hline SFO & May 2003 \\
\hline SLC & November 2003 \\
\hline MCO & August 2002 \\
\hline
\end{tabular}

The metrological information provided by ASPM includes general weather, i.e. instrument meteorological condition (IMC) or visual meteorological condition (VMC), lowest ceiling height, visibility, temperature, wind direction, and wind speed. Since the runway configuration is also available, the tailwind and crosswind factors are calculated. The same information was computed for accidents using data from the NTSB accident database.

To ensure accuracy, an accident was eliminated if its weather information is recorded from an observation facility that is more than 10 nautical miles from the accident site. 30 accidents were removed as a result, with 253 remaining (93 LDUS, 28 TOCs, 19 TOORs and 113 LDORs). The accident and normal flights data were also reconfigured to ensure consistency and comparability.

\section{ACCIDENT DATA VERSUS NOD ANALYSIS}

\section{Comparisons of Means}

As an initial investigation of the difference in exposure to weather parameters between normal and accident flights, chi-square and t-tests was performed on the two sets of data to detect significant differences in means and the related effect sizes. This conducted on each accident type independently. Take-off accidents are compared to normal take-off operations and landing accidents to normal landing operations (Table 2). .

Table 2 Chi-square and t-test results with effect size measures

\begin{tabular}{|l|l|l|l|l|}
\hline & LDOR & LDUS & TOC & TOOR \\
\hline General Weather & & & & \\
\hline $\begin{array}{l}\text { Pearson chi-square } \\
\text { Sig.) }\end{array}$ & $100.82(0.00)$ & $80.12(0.00)$ & $8.27(0.00)$ & $6.58(0.01)$ \\
\hline Phi (Sig.) & $0.03(0.00)$ & $0.02(0.00)$ & $0.01(0.00)$ & $0.01(0.01)$ \\
\hline Odds ratio & 5.47 & 5.38 & 2.93 & 3.010 \\
\hline
\end{tabular}




\begin{tabular}{|l|l|l|l|l|}
\hline Visibility & & & & \\
\hline $\mathrm{t}$ (Sig.) & $13.77(0.00)$ & $10.81(0.00)$ & $5.03(0.00)$ & $3.88(0.00)$ \\
\hline $\mathrm{r}$ & 0.79 & 0.75 & 0.70 & 0.67 \\
\hline Ceiling & & & & \\
\hline $\mathrm{t}$ (Sig.) & $17.72(0.00)$ & $16.82(0.00)$ & $9.88(0.00)$ & $5.35(0.00)$ \\
\hline $\mathrm{r}$ & 0.89 & 0.87 & 0.89 & 0.78 \\
\hline Temperature & & & & \\
\hline $\mathrm{t}$ (Sig.) & $9.82(0.00)$ & $8.70(0.00)$ & $3.29(0.00)$ & $4.20(0.00)$ \\
\hline $\mathrm{r}$ & 0.02 & 0.02 & 0.01 & 0.01 \\
\hline Crosswind & & & & \\
\hline $\mathrm{t}$ (Sig.) & $-0.97(0.33)$ & $-0.74(0.46)$ & $-0.51(0.61)$ & $-1.53(0.14)$ \\
\hline $\mathrm{r}$ & 0.09 & 0.00 & 0.10 & 0.34 \\
\hline Tailwind & & & & \\
\hline $\mathrm{t}$ (Sig.) & $5.00(0.00)$ & $0.32(0.75)$ & $1.22(0.22)$ & $0.11(0.92)$ \\
\hline $\mathrm{r}$ & 0.43 & 0.03 & 0.00 & 0.00 \\
\hline
\end{tabular}

The chi-square analysis on instrument/visual meteorological conditions shows it to have a significant association with the occurrence of all accident types. The phi statistic, however, suggests a stronger relationship between general weather and landing accidents than their take-off counterparts. The odds ratios indicate that while an accident is approximately 5.4 times more likely under IMC than VMC for landing accidents, take-off accidents are only about 3 times more likely.

The t-test results show significant differences in the means of visibility, ceiling and temperature between accident and normal flights, suggesting that the two groups of flights are exposed to generally different meteorological conditions. For example, visibility was significantly lower for crashes after take-off than normal take-off operations. The strength of association is not uniform across parameters and accident types. Both visibility and ceiling have high $\mathrm{r}$-values but while effect size appears fairly consistent across all accident types for ceiling, visibility's strength of association seems stronger for landing than take-off accidents. On the other hand, even as the difference in means is statistically significant for temperature, the effect size is small for all accident types.

The results indicate that, on average, accident and normal flights experience similar levels of crosswind and tailwind. This appears to contradict the notion that adverse wind conditions are conducive to accident occurrence. Moreover, the only significant difference in terms of wind exposure is also counterintuitive - landing overruns on average experience significantly lower tailwind (mean of 1.75knots) than normal landings (mean of 3.37knots).

\section{Relative Accident Involvement Ratio}

Enders et al. (1996) used the "Risk Ratio" to estimate the risk of an approach and landing accident with a particular factor present. It is calculated as:

Risk Ratio $=(\mathrm{a} / \mathrm{A}) /(\mathrm{f} / \mathrm{N})$

where; $\mathrm{a}$ is numbers of occurrences of a factor in accidents, $\mathrm{A}$ is number of accidents, $\mathrm{F}$ is number of occurrences of the factor in normal flights, and $\mathrm{N}$ is number of normal flights 
The same measure but called the relative accident involvement ratio (RAIR) is well established in road transport safety research as a measure of accident propensity among driver groups. Ratios over unity indicate that the subgroup of drivers concerned is more likely to cause a crash under the circumstances considered (Stamatiadis and Deacon, 1994, 1996, Hing et al., 2003, Yan et al., 2003). Here the measure is used to evaluate the accident propensity of flights under different weather conditions. So while the t-tests and chi-square analyses have compared accident and normal operations data in terms of their mean values of exposure to weather parameters, RAIR $^{2}$ analysis investigates the differences in exposure to varying degrees of these parameters.

For each parameter, the range of values is split into quintiles and the RAIR for each quintile calculated. This provides a simple description of fight accident propensity associated with different strengths of the parameter concerned. In cases where accident propensity is highly concentrated in a particular quintile, it is split into finer groups and the RAIRs recalculated (Table 3).

Table 3 Relative Accident Involvement Ratio

\begin{tabular}{|c|c|c|c|c|}
\hline & LDOR & LDUS & TOC & TOOR \\
\hline \multicolumn{5}{|l|}{$\begin{array}{l}\text { General } \\
\text { Weather }\end{array}$} \\
\hline IMC & 2.97 & 2.91 & 3.21 & 2.21 \\
\hline VMC & 0.55 & 0.54 & 0.71 & 0.71 \\
\hline \multicolumn{5}{|l|}{ Visibility (sm) } \\
\hline $0-2$ & 24.47 & 19.24 & 19.64 & 18.42 \\
\hline $2-4$ & 7.01 & 9.58 & 3.70 & 2.73 \\
\hline $4-6$ & 2.48 & 2.01 & 2.20 & 3.24 \\
\hline $6-8$ & 1.15 & 0.88 & 1.65 & 0.81 \\
\hline $8-10$ & 0.30 & 0.38 & 0.41 & 0.49 \\
\hline & & & & \\
\hline $0-0.2$ & 6054.60 & 6058.42 & 23215.14 & 25658.84 \\
\hline $0.2-0.4$ & 12.00 & 3.64 & 8.55 & 0.00 \\
\hline $0.4-0.6$ & 20.11 & 28.51 & 11.65 & 0.00 \\
\hline $0.6-0.8$ & 21.32 & 8.63 & 14.92 & 21.99 \\
\hline $1-1.2$ & 48.20 & 26.03 & 45.97 & 33.87 \\
\hline $1.2-1.4$ & 0.00 & 5.15 & 0.00 & 0.00 \\
\hline 1.4-1.6 & 0.00 & 0.00 & 0.00 & 14.23 \\
\hline $1.6-1.8$ & 0.00 & 0.00 & 0.00 & 0.00 \\
\hline $2-2.2$ & 9.30 & 12.56 & 4.52 & 6.66 \\
\hline $2.4-2.6$ & 3.66 & 2.22 & 0.00 & 0.00 \\
\hline $2.8-3$ & 6.49 & 11.05 & 5.80 & 0.00 \\
\hline$>3$ & 0.42 & 0.47 & 0.56 & 0.60 \\
\hline Ceiling (00ft) & & & & \\
\hline
\end{tabular}

${ }^{2}$ RAIR is preferred to risk ratio as the latter usually refers to a different measure in statistics. 


\begin{tabular}{|c|c|c|c|c|}
\hline $1-6$ & 24.46 & 21.46 & 19.28 & 12.18 \\
\hline $7-12$ & 7.38 & 9.86 & 4.32 & 8.50 \\
\hline $13-18$ & 2.51 & 0.55 & 0.86 & 3.82 \\
\hline $19-24$ & 1.15 & 1.05 & 2.36 & 0.00 \\
\hline $25-30$ & 0.21 & 0.20 & 0.16 & 0.35 \\
\hline $1-1$ & 000 & 2535 & 2150 & 000 \\
\hline $2-2$ & 82.59 & 25.09 & 95.93 & 70.69 \\
\hline $3-3$ & 96.04 & 58.35 & 30.87 & 45.49 \\
\hline $4-4$ & 66.26 & 80.51 & 0.00 & 0.00 \\
\hline $5-6$ & 2.43 & 7.37 & 10.55 & 7.78 \\
\hline \multicolumn{5}{|l|}{ Temperature (C) } \\
\hline$-25--10$ & 2.50 & 1.52 & 0.00 & 2.43 \\
\hline$-10-5$ & 2.53 & 3.14 & 2.42 & 3.21 \\
\hline $5-20$ & 1.46 & 1.15 & 1.45 & 0.77 \\
\hline $20-35$ & 0.35 & 0.36 & 0.44 & 0.44 \\
\hline $35-50$ & 0.11 & 0.26 & 0.46 & 0.68 \\
\hline \multicolumn{5}{|l|}{$\begin{array}{l}\text { Crosswinds } \\
\text { (knots) }\end{array}$} \\
\hline $0-6$ & 0.96 & 1.01 & 0.98 & 0.84 \\
\hline $6-12$ & 0.91 & 0.94 & 0.84 & 1.03 \\
\hline $12-18$ & 1.48 & 0.90 & 0.78 & 1.15 \\
\hline $18-24$ & 4.39 & 2.67 & 7.75 & 11.42 \\
\hline $24-30$ & 0.00 & 0.00 & 0.00 & 0.00 \\
\hline $12-14$ & 1.74 & 0.85 & 1.45 & 2.14 \\
\hline $14-16$ & 1.28 & 1.55 & 0.00 & 0.00 \\
\hline $16-18$ & 1.02 & 0.00 & 0.00 & 0.00 \\
\hline $18-20$ & 4.64 & 0.00 & 5.60 & 0.00 \\
\hline $20-22$ & 6.06 & 7.37 & 21.98 & 32.40 \\
\hline $22-24$ & 0.00 & 12.28 & 0.00 & 43.42 \\
\hline \multicolumn{5}{|l|}{ Tailwind (knots) } \\
\hline $0-5$ & 1.24 & 1.10 & 1.23 & 1.09 \\
\hline 5-10 & 0.32 & 0.49 & 0.17 & 0.74 \\
\hline $10-15$ & 0.45 & 1.27 & 1.28 & 0.94 \\
\hline $15-20$ & 2.46 & 1.49 & 0.00 & 0.00 \\
\hline $20-25$ & 0.00 & 55.84 & 0.00 & 0.00 \\
\hline $15-17$ & 3.94 & 2.39 & - & - \\
\hline $17-19$ & 0.00 & 0.00 & - & - \\
\hline $19-21$ & 0.00 & 0.00 & - & - \\
\hline $21-23$ & 0.00 & 69.24 & - & - \\
\hline $23-25$ & 0.00 & 0.00 & - & - \\
\hline
\end{tabular}


Accident data alone shows that $55 \%$ of landing overruns occurred in IMC and $45 \%$ in VMC. This may lead to belief that landing overruns are similarly likely to occur in IMC as in VMC, but when the exposure information is considered only $18 \%$ of normal flights operate under IMC. The RAIRs reflect this and show IMC's association with accidents as much stronger than VMC's for all accident types. The results suggest that an accident is 3 to 5 times more likely to occur under IMC, confirming the chi-square analysis.

Computing RAIRs goes beyond average exposure to consider different levels of risk exposure and characterises the parameters as risk factors in relevant accidents. Two families of risk factors were identified. The first comprises of "continuous" risk factors, the exposure to which is very different across the range of factor strengths between normal and accident flights. The strength of the factor has a mono-directional impact on accident risk. Visibility and ceiling clearly belong to this group.

The first set of RAIRs for visibility reveal a clear trend in the parameter's relationship with accident propensity. As shown in Figure 1, there is a gradual decrease in accident propensity as visibility increases. This confirms and quantifies the idea of heightened accident risk in low visibility conditions.

Figure 1 Visibility RAIR

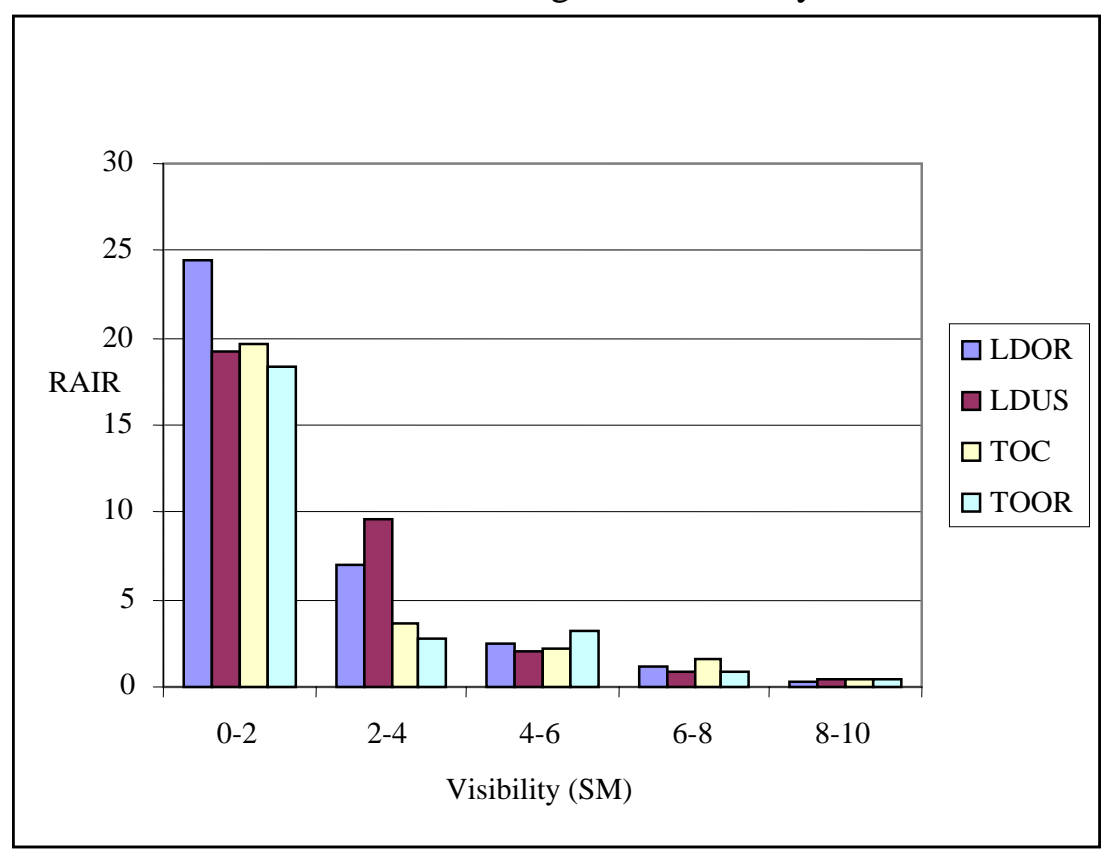

The high values in the second set of visibility RAIRs for category 0 to 0.2 miles is related to the relatively large proportion of accidents occurring in range of visibility conditions (14.3\% to $15.8 \%$ ) and the rarity of such conditions in the exposure data (under $0 \%$ for both landing and take-off). The large difference between landing and take-off RAIRs in this category is related to the higher share of normal take-offs than landings in this visibility range (rather than a difference in their respective shares of accidents), as well as the small base numbers for RAIR calculation. This also explains visibility's larger effect 
on landing than take-off accidents as found in the t-test analysis. The peaks at categories including whole numbers such as $0,1,2$ and 3 miles are probably due to accident investigators' rounding of visibility figures. Nonetheless, the trend of decreasing accident propensity with higher visibility is still evident.

Similar to visibility, a clear trend can be found in the ceiling RAIR results. The first set of results shows that low ceiling conditions are associated with high accident propensity, which decreases with higher ceiling heights. The results are similar across accident types. However, the slightly higher figures for landings accidents at the low-end of ceiling conditions suggests that low ceiling conditions are somewhat more pertinent to landings as an accident risk factor than for take-offs. RAIRs are all below $1 \mathrm{for}$ the 2500 to $3000 \mathrm{ft}$ category, implying that accidents are relatively unlikely when ceiling is above $2500 \mathrm{ft}$. The second set of ceiling RAIRs shows high risk categories distributed in the 100 to $400 \mathrm{ft}$ range without a prominent trend.

The second family of risk factors may be described as discrete. They display pockets of high risk or thresholds of risk above which accident propensity is markedly high. Outside these special ranges, accident and normal flight exposure to the risk factor are similar. Wind conditions and temperature belong to this family of risks.

Rather than a gradual increase in RAIR with higher crosswind, the figures remain fairly stable at around 1 throughout the categories from 0 knots to 18 knots. However, the 18 to 24 knots category has much higher RAIRs (Figure 2). This suggests that unlike ceiling or visibility where risk gradually increases with worsening conditions, crosswind is not so much a risk factor until it reaches the 18 knots threshold. No accidents occurred with crosswind above 24knots hence the zero RAIRs. Further examination of the 12 to 24 knots range yields many categories with RAIRs of zero, suggesting that the results are highly influenced by individual cases, especially for take-off accidents. Nonetheless, it confirms the generally high relative accident propensity of crosswind conditions above 18 knots.

Figure 2 Crosswind RAIR 


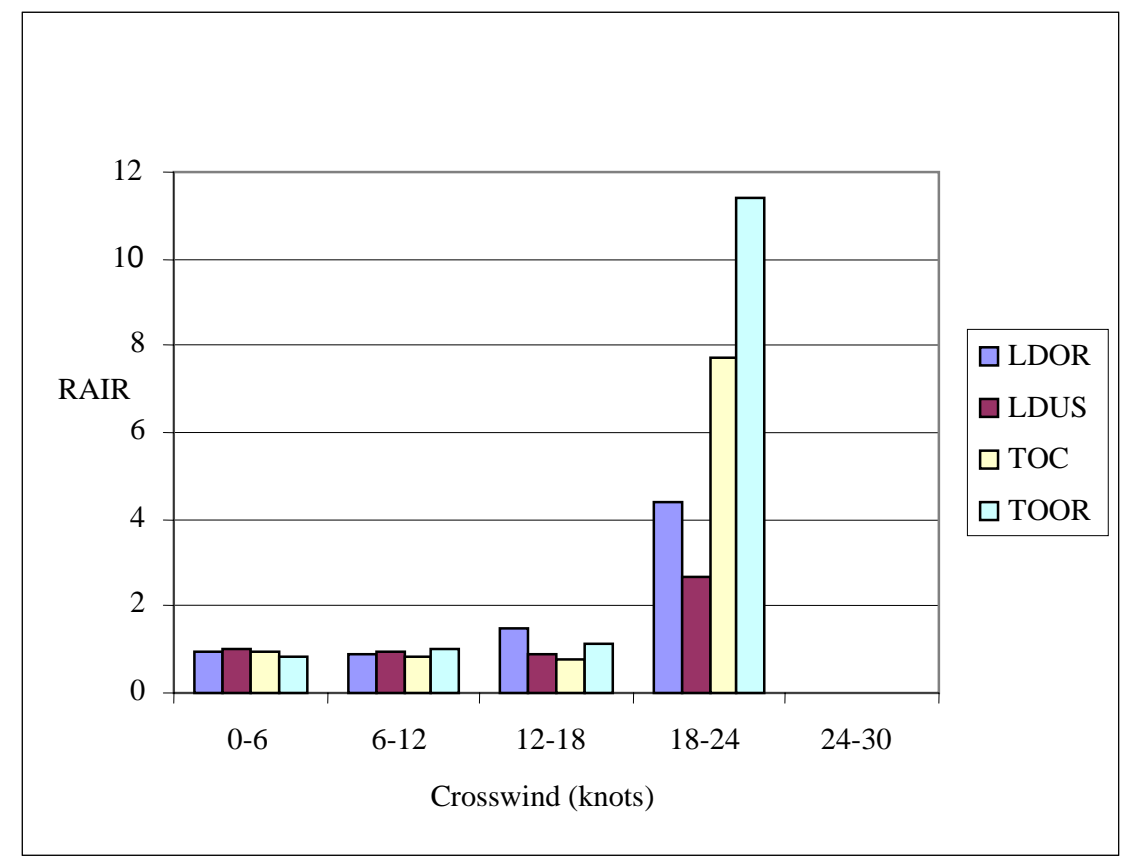

These results echo and account for the unexpected t-test findings, that suggested the crosswind experienced by accidents are similar to normal flights. RAIR analysis revealed the discrete nature of crosswind as an accident risk factor - high accident propensity is only associated with crosswind above a certain threshold. Under this critical threshold, the crosswind experienced by the majority of accidents and normal flights are indeed similar. In the t-test, this majority overshadows the small number of accidents with high crosswind between 18 and 24 knots (10.5\% for takeoff overruns is the highest amongst the four accident types).

Similar to crosswind, the analysis on tailwind failed to produce a continuous trend in accident propensity. For LDORs and LDUSs, pockets of relative high risk are found in the 15-20 knots and 20-25 knots categories respectively. Unlike other parameters studied, the lowest category (0-5knots) has relatively high RAIRs compared to the higher strength categories. This implies that accidents are more likely to occur in light tailwind conditions than stronger tailwind conditions, although the difference is relatively small. This mirrors the unusual t-test result that showed higher average tailwind exposure for normal flights than landing overruns. A deeper investigation reveals that $64 \%$ of landing overruns experience 0 tailwind but the corresponding figure for normal landings is only $37 \%$. However, the figures may hide other pertinent risk factors not covered in the study, e.g. wind gusts. The effects of individual cases can again be seen in the second set of results. Further analysis was not conducted for take-off accidents since tailwind is not shown to be significantly associated with take-off accidents across the initial range of tailwind conditions.

The RAIR figures for temperature (Figure 3) suggest that accident propensity is not as sensitive to temperature as to visibility or ceiling, confirming the small effect size of the t-tests. However, RAIRs for the -10C-5C category suggests substantially higher risk than 
categories of above 5C. RAIRs peak at the -10C to 5C category with lower RAIRs in every other temperature group, irrespective of accident type. This points to the relatively high risk associated with freezing and icing conditions.

Figure 3 Temperature RAIR

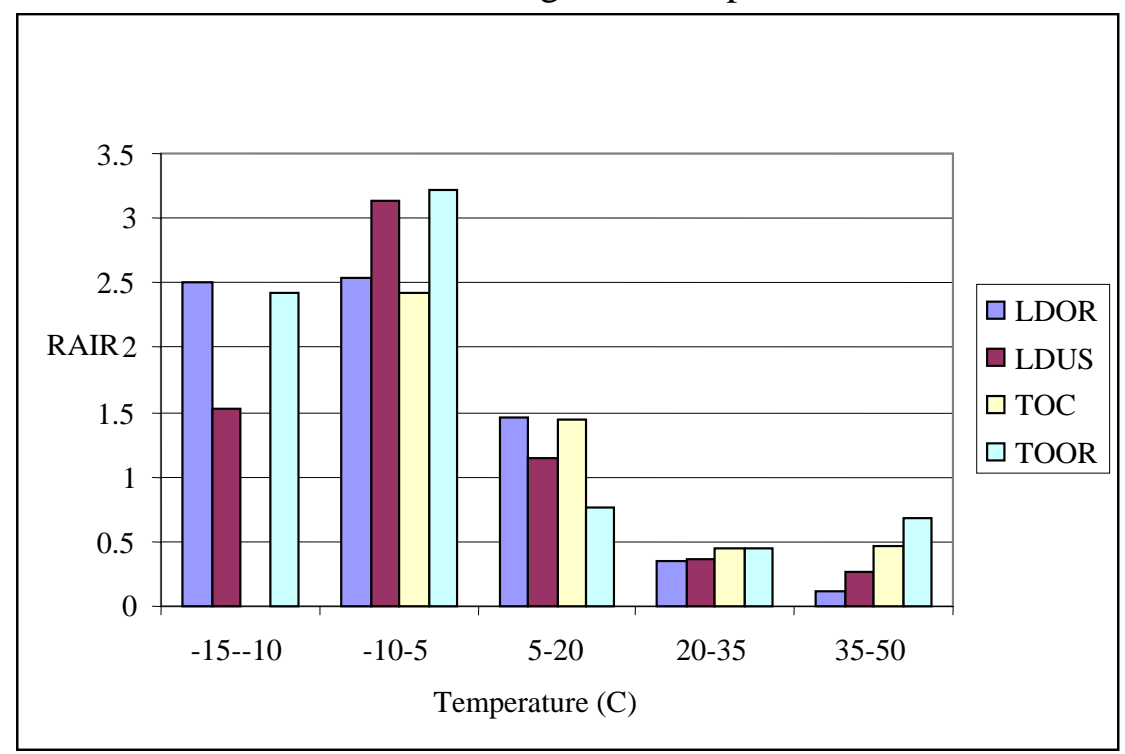

\section{CONCLUSION}

The use of normal operations data in understanding and analysing aviation accidents lacks substantial research. Previous work making use of normal flight data covered a number of parameters but pointed to meteorological conditions as an important area that deserves examination. Using statistical techniques, the nature and criticality of weatherrelated parameters as risk factors in aviation accidents were explored here. The study identified and quantified two broad families of risk factors - continuous and discrete. Conducting the analysis on the different accident types independently yielded additional findings on the difference in vulnerability between take-off and landing operations.

\section{REFERENCES}

Ashford, R. (1998), Approach and landing fatal accidents 1980-1996, Safety Analysis Report No. SA-98002, Civil Aviation Authority, London.

Enders, J., Doff, R., Tarrel, R., Khatwa, R., Roelen, Al., Karwal, A. (1996). Airport safety: A study of accidents and available approach-and-landing aids. Flight Safety Digest March. Flight Safety Foundation, Alexandria..

Federal Aviation Administration (2002), Documentation for the Aviation System Peformance Metrics (ASPM), Office of Aviation Policy and Plans, Federal Aviation Administration, Washington, DC.

Hing, J.Y.C., Stamatiadis, N., Aultman-Hall, L. (2003) "Evaluating the impact of passengers on the safety of older drivers” Journal of Safety Research, 34, 343-351. 
Khatwa, R., Helmreich, R.L. (1998), Killers in aviation: Analysis of critical factors during approach and landing in accidents and normal flight, final report version 2.0 ed., Flight Safety Foundation, Alexandria.

Kirkland, I., Caves, R., Humphreys, I., Pitfield, D. (2004). “An improved methodology for assessing risk in aircraft operations at airports, applied to runway overruns” Safety Science, 42, 891-905.

Piers, M.A,. Loog, M.P., Giesberts, M.K.H., Moek, G., Couwenberg, M.J.H., Smeets, M.C.J. (1993), The development of a method for the analysis of societal and individual risk due to aircraft accidents in the vicinity of airports, National Aerospace Laboratory, Amsterdam,.

Stamatiadis, N., Deacon, J.A. (1995), “Trends in highway safety: effects of an aging population on accident propensity”, Accident Analysis and Prevention, 27, 443-459.

Stamatiadis, N., Deacon, J.A. (1997), “Quasi-induced exposure: methodology and insight”, Accident Analysis and Prevention, 29, 37-52.

Yan, X., Radwan, E., Abdel-Aty, M. (2005), "Characteristics of rear-end accidents at signalized intersections using multiple logistic regression model” Accident Analysis and Prevention, 37, 983-995. 